\title{
An assessment of ergonomic issues in the home offices of university employees sent home due to the COVID-19 pandemic
}

\author{
Thomas Gerding ${ }^{\mathrm{a}, *}$, Megan Syck ${ }^{\mathrm{a}}$, Denise Daniel ${ }^{\mathrm{b}}$, Jennifer Naylor ${ }^{\mathrm{b}}$, Susan E. Kotowski ${ }^{\mathrm{c}}$, \\ Gordon L. Gillespie ${ }^{\mathrm{b}}$, Andrew M. Freeman ${ }^{\mathrm{a}}$, Thomas R. Huston ${ }^{\mathrm{d}}$ and Kermit G. Davis ${ }^{\mathrm{a}}$ \\ ${ }^{a}$ Department of Environmental and Public Health Science, College of Medicine, University of Cincinnati, \\ Cincinnati, $\mathrm{OH}, \mathrm{USA}$ \\ ${ }^{\mathrm{b}}$ College of Nursing, University of Cincinnati, Cincinnati, $\mathrm{OH}, \mathrm{USA}$ \\ ${ }^{\mathrm{c}}$ Department of Rehabilitation, Exercise and Nutrition Sciences, College of Allied Health Sciences, \\ University of Cincinnati, Cincinnati, $\mathrm{OH}, \mathrm{USA}$ \\ ${ }^{\mathrm{d}}$ Department of Mechanical Engineering, College of Engineering and Applied Sciences, University of Cincinnati, \\ Cincinnati, OH, USA
}

Received 5 December 2020

Accepted 27 January 2021

\begin{abstract}
.
BACKGROUND: As millions of workers have shifted to telework, special accommodations for workers with respect to ergonomics may be required to ensure the workforce remains healthy.

METHODS: A survey about home office ergonomics and discomfort was sent to faculty, staff, and administrators by email and was completed by 843 individuals.

RESULTS: Over $40 \%$ of the participants reported moderate to severe discomfort (severe low/middle back pain, moderate discomfort in eyes/neck/head, and discomfort in the upper back/shoulders). Laptops (always and often) were widely used (85\%) with most using the laptop monitor (55\%) of all respondents. Further, less than $45 \%$ of the seating conditions were reported as having adjustable arm rests.

CONCLUSION: As teleworking in makeshift offices becomes more common, the risk of significant discomfort and potentially more serious musculoskeletal disorders may result from poor static postures. Companies may need to accommodate workers by allowing them to take home office chairs, external monitors, keyboards, and mice as laptops are insufficient, ergonomically.
\end{abstract}

Keywords: Telework, musculoskeletal disorder, human-computer interface

\section{Introduction}

According to the United States (U.S.) Census Bureau, there were over 128 million full-time employees in the U.S. in 2019, with some employees working from home [1]. The U.S. Bureau of Labor Statistics states the number of people working a portion or all

*Address for correspondence: Thomas Gerding, Kettering Laboratory Room 133, 160 Panzeca Way, Cincinnati, Ohio 45267, USA. E-mail: gerdintr@mail.uc.edu. their hours from home increased from $19 \%$ in 2003 to $24 \%$ in 2015 [2]. While many occupations (e.g., manufacturing, construction, warehousing) were less likely to work from home, $38 \%$ of management, business, and financial operations and $35 \%$ of professional workers worked at least partially remote. Remote work, work from home, virtual work, or telecommuting (hereafter referred to as telework), which was developed in the 1970s, involves different work strategies using information and communication technologies such as desktop computers, laptops, 
tablets, or smartphones for work that is completed outside the employer's buildings [3]. Telework has traditionally allowed workers to save time and money otherwise spent on commuting, but in the current environment, its value is also reducing the risks regarding employees gathering at work during the ongoing pandemic.

The spread of the novel coronavirus (COVID-19) was classified as a global pandemic by the World Health Organization on March 11, 2020 [4]. Following this, the United States declared health emergencies at the federal and state level, with every state individually declaring an emergency associated with the stay-at-home quarantine policy. These policies caused many U.S. workers to transition to work in a home office abruptly. Telework was thrust upon millions of people, some estimates of more than $55 \%$ of the U.S. workforce will work at home during the next two years [5].

Telework has been studied since the turn of the century, with findings ranging from both beneficial and detrimental outcomes $[6,7]$ In a survey of IBM employees who provided self-assessment of their subjective performance, those working in a virtual office were more likely to report a willingness to give extra effort towards helping their company succeed, more motivation, and higher job retention rates than those working in a traditional office [6]. Although telework implementation is thought to strengthen an individual's work/life balance, a worsened work/life balance was found in prior research [6]. Here, the obstacles faced by teleworkers may be a combination of the ability to perform multiple, distinct (work/domestic) tasks at once and a lack of externally imposed physical boundaries, muddying the distinction between work-life and home-life areas/spaces [6].

Unfortunately, this transition to telework has become a "new normal" phenomenon which may ultimately result in emerging ergonomic issues. Regardless of where work is completed, poor posture while operating a computer or laptop can cause stiffness, soreness, back pain, sore neck, and eye fatigue. However, laptop use has been found to have a greater risk [8]. Additionally, the chair height and the armrest position has been associated with musculoskeletal pain if positioned or used improperly [9]. Current home office arrangements may range from a computer atop a kitchen table, a laptop used in a recliner, or work being completed while sitting in a bed or on the floor [10]. None of these workstations are geared for completing a full day of work, especially from an ergonomic perspective. For example, the use of a laptop while seated on a couch caused awkward wrist postures while typing on the keyboard or activation of the touchpad, arms not supported, placing stress on the upper back, and neck flexed to look down at the screen [11]. Individuals using external input devices such as a keyboard and mouse tend to report less computer-related discomfort than laptop devices [12].

While there is ample published evidence regarding the relationship between poor office ergonomics and a heightened risk of musculoskeletal injuries [13-17], there is not much evidence that exists regarding workstations in telework, including home-based work environments necessitated by the COVID-19 pandemic. The study's goal was to survey the faculty, staff, and administrators at a large public urban Midwestern university about their home office, specifically the ergonomic stressors and muscular discomfort, to characterize the prevalence of these stressors and discomfort. In addition, correlation and regression analyses were conducted to investigate the relationship between office exposures and discomfort.

\section{Methods}

\subsection{Study design}

The survey was a cross-sectional evaluation of the conditions in the home offices of the university's employees. On April 14, 2020, a survey investigating the ergonomic stressors and discomfort for home offices was sent to all staff, administration, and faculty members of the University of Cincinnati.

\subsection{Home office survey}

The survey was developed in REDCap (Cincinnati Children's Hospital Medical Center, Cincinnati, $\mathrm{OH})$. The survey inquired about demographic information: employment position at the university, age, and gender; type of computer device used: laptop, desktop, tablet, or another device; type of chair used: office chair with armrests, office chair without armrests, kitchen/dining chair, folding chair, couch or sofa, bed, armchair or recliner, or other types of seating; type of monitors: built-in laptop screen, external monitor, two stand-external monitors, laptop screenexternal monitor combination, or other; type of input device used: built-in keyboard, external keyboard, traditional mouse, built-in mouse pad, trackball, 
touch screen, stylus, or other input devices; and type of worksurface used: traditional desk, makeshift desk, sit/stand workstation store-bought, makeshift sit/stand workstation, not on a work surface, or another work surface. The factors were rated as always, often, sometimes, seldom, or never used concerning the time spent on average per working day following the beginning of working from home. The survey also asked about the respondents' stress/ tiredness level relative to the typical stress and fatigue levels experienced in the typical office setting. Additionally, the level of discomfort in body regions, including head/neck/eyes, upper back/shoulders, and lower back, was investigated. A final section for open comments was provided for respondents to express additional concerns.

\subsection{Study population}

This study was specifically limited to faculty, staff, and administration employed by the University of Cincinnati, with a population of nearly 10,350 individuals [18]. Of this population, 843 individuals returned surveys about their home office that resulted from the ongoing COVID-19 pandemic.

\subsection{Data analyses plan}

Descriptive statistics were determined for each variable, including frequency and percentage of samples responded. Statistical analyses consisted of univariate correlations of all ergonomic exposures and discomfort variables and linear regression models. Two sets of regression models were developed utilizing stepwise regression and theoretical a priori models: 1) set of models predicted the 9-body regions based on the workplace exposure variables, and 2) set of models predicted the tiredness and stress based on the workplace exposure variables. All regression relationships were significant, as defined by having a $p$-value $<0.05$.

\section{Results}

\subsection{Workplace concerns}

Overall, 843 surveys were completed (see Table 1). Most respondents were faculty $(n=577)$, followed by staff $(n=227)$ and administration $(n=20)$. A majority of the respondents were female $(n=509,60 \%)$. More than half of the survey population $(54 \%)$ were 50 years of age or under $(n=456)$.

Device usage can be found in Fig. 1 and reveals laptops are widely used in home offices. Nearly $70 \%$ $(n=579)$ of the participants reported using a laptop "always", while $15 \%(n=115)$ and $3 \%(n=23)$

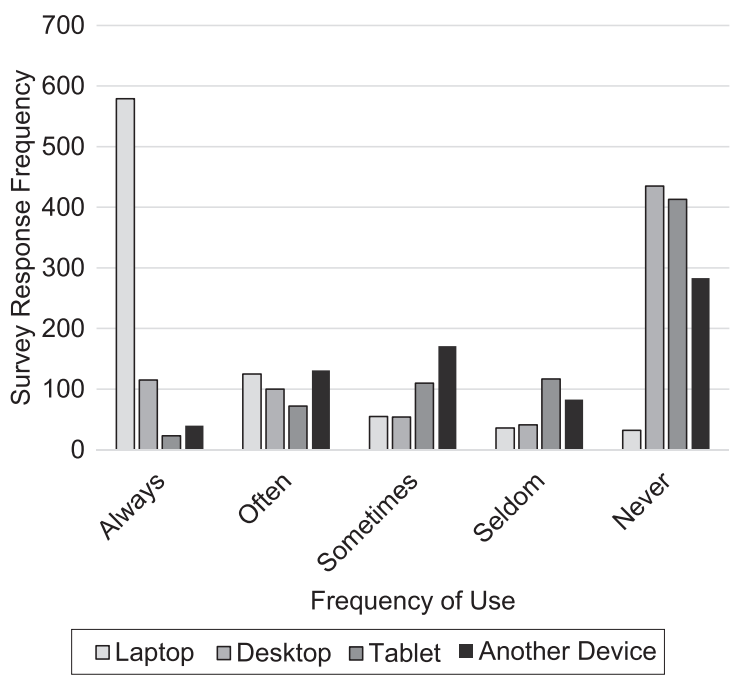

Fig. 1. Frequency of use for each computer type.

Table 1

Demographic information of survey respondents

\begin{tabular}{lccccc}
\hline & Faculty & Staff & Administration & No response & Overall \\
\hline Total & 577 & 227 & 20 & 19 & 843 \\
Age less than 30 & 7 & 29 & 0 & & 36 \\
Age 31 to 40 & 121 & 78 & 2 & & 201 \\
Age 41 to 50 & 162 & 52 & 5 & & 219 \\
Age 51 to 60 & 163 & 40 & 9 & & 212 \\
Age 61 to 70 & 99 & 25 & 4 & 19 & 128 \\
Age 71 and above & 21 & 3 & 0 & & 24 \\
No response & 4 & 0 & 0 & & 23 \\
Male & 223 & 60 & 6 & & 509 \\
Female & 337 & 160 & 12 & 19 & 1 \\
Other & 0 & 1 & 0 & & 44 \\
No response & 17 & 6 & 2 & & \\
\hline
\end{tabular}




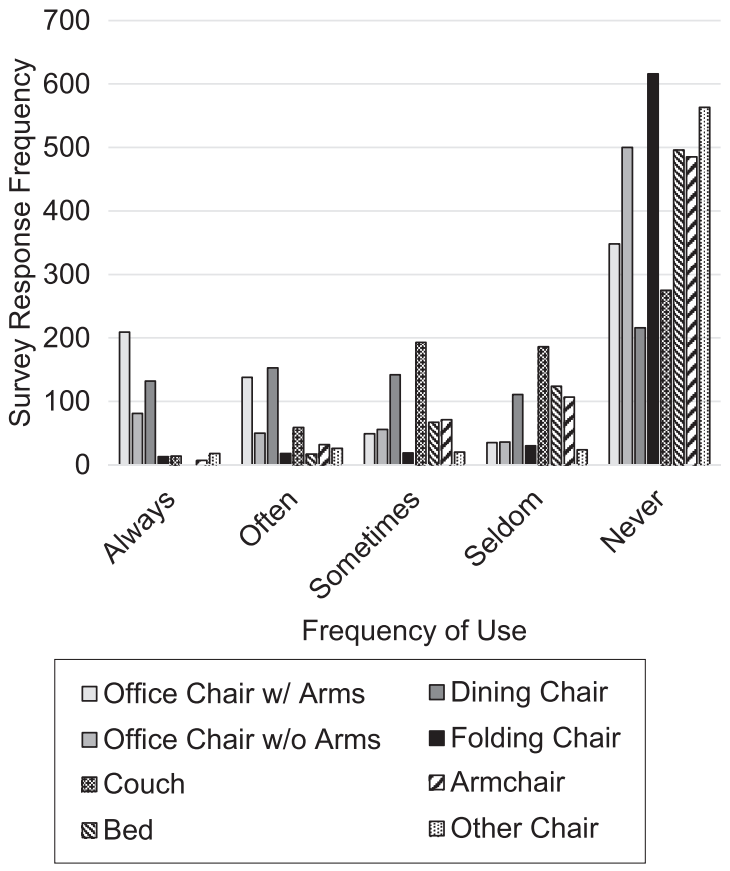

Fig. 2. Frequency of use for each chair type.

reported always using a desktop and tablet, respectively. Another device, which was predominantly a mobile device, was used "often" or "sometimes" about $43 \%$ of the time.

The type of chair used in the home office seemed to vary widely between participants (see Fig. 2). While $44.6 \%$ ( $n=347)$ of the participants reported "always" or "often" using an office chair with armrests- the recommended seat from an ergonomic perspective, many use chairs with no armrests as $44.7 \%(n=348)$ reported never using an office chair with armrests. The extensive usage of chairs without armrests was widely prevalent as respondents reported "always", "often" or "sometimes" for usage of dining chair $56.6 \%(n=427)$, couch $36.6 \%(n=266)$, folding chair $7.2 \%(n=50)$, bed $12.0 \%(n=84)$, and armchair $15.7 \%(n=110)$. Additionally, these chairs were often sub-optimal with no adjustable arms and lumbar support. Indeed, only $21.6 \%(n=182)$ of the respondents reported using a chair with adjustable armrests and $30 \%(n=253)$ reported using a chair with either built-in lumbar support or lumbar support which had been added to the chair. Another chair related factor that can cause problems to the worker is the lack of proper support to the back from the chair. Roughly two-thirds of respondents $(n=534,64.4 \%)$ noted they "sometimes", "seldom", or "never" have their back in contact with their chair.
Regarding the screen options used in the home office, many respondents reported "always" using a built-in laptop screen $(n=435,55.1 \%)$ while also reporting "never" using alternative (external monitor, $n=426$ or $60.4 \%$, two external monitors, $n=554$, $83.1 \%)$ or supplemental monitor to the laptop ( $n=$ $414,56.6 \%$ ) (as seen in Fig. 3). Similarly, regarding

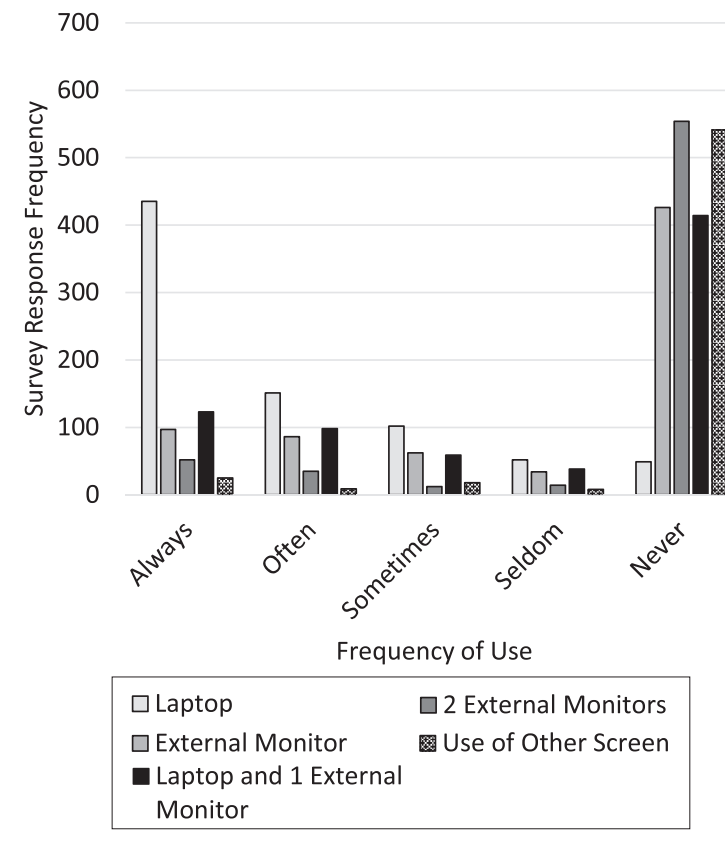

Fig. 3. Frequency of use for each screen type.

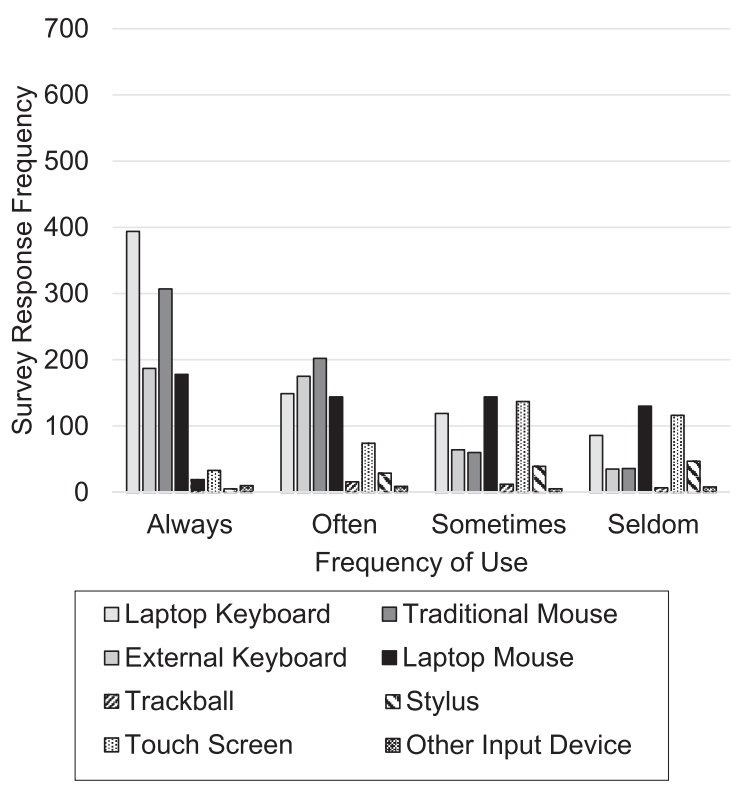

Fig. 4. Frequency of use for each input device. 


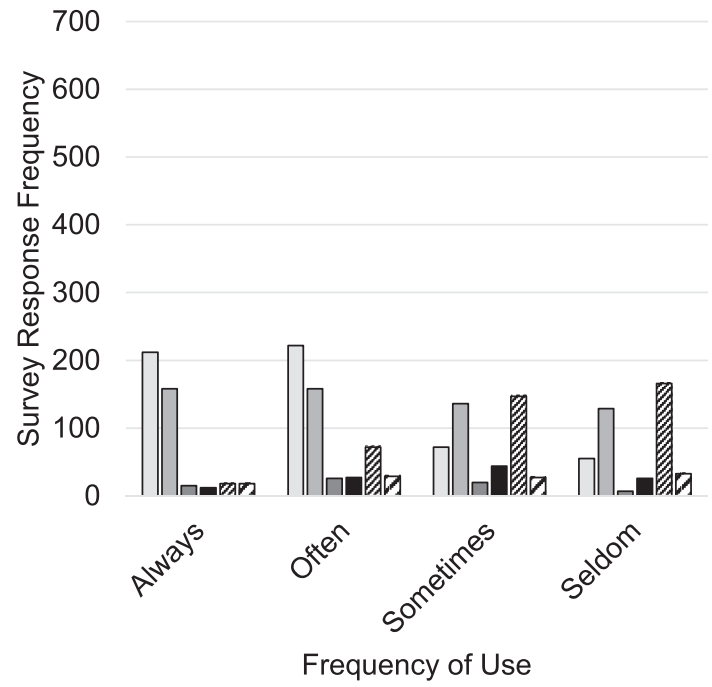

\begin{tabular}{|ll|}
\hline$\square$ Traditional Desk & Makeshift Sit/Stand Desk \\
$\square$ Makeshift Desk & No worksurface \\
$\square$ Bought Sit/Stand Desk & $\square$ Other Worksurface
\end{tabular}

Fig. 5. Frequency of use for each workstation type.

input devices, many responded "always" using a laptop keyboard, albeit with an external mouse, but never using more ergonomically friendly tools such as an external keyboard. As seen in Fig. 4, 46.7\% ( $n=394)$ of respondents reported "always" using a laptop keyboard compared to $21.8 \%(n=187)$ "always" using an external keyboard. A similar pattern was observed with the use of a mouse as $36.4 \%(n=307)$ of respondents reported "always" using a traditional mouse, 21.1\% ( $n=178)$ reported "always" using a laptop mouse.

The results were fairly mixed with regard to the type of workstation being utilized while in the home office (Fig. 5). While greater than half of the respondents $(n=434,54.8 \%)$ stated they "always" or "often" use a traditional desk, the remainder appear to work from either makeshift desks $(n=316,41.0 \%)$ or no worksurface at all $(n=90,12.3 \%)$. Few respondents utilized a sit-stand workstation "always" or "often" (store bought $n=41,5.7 \%$, makeshift $n=39$, $5.5 \%)$. With many of the workstations, users often had to type in the presence of a hard-front edge of the worksurface. Nearly half of the respondents $(n=390$, $52.1 \%$ ) noted their desk had a sharp edge along the front.

Many of the workstations and working practices yielded poor body postures. There were many participants who perceived poor postures when working at home such as roughly $40 \%(n=323)$ stated their backs were bent "always", "often", or "sometimes" and nearly three-fourths $(n=625)$ reported their head/neck being tilted forward "always", "often", or "sometimes". In addition, $18 \%(n=153)$ and $28 \%$ $(n=234)$ of respondents reported their head/neck was tilted backward or sideways, respectively.

Approximately half of the respondents $(n=426)$ reported glare was present on their worksurface and/ or screen "always", "often", or "sometimes". Nearly three-fourths of respondents $(n=603)$ reported they work for a duration greater than one hour without taking a break. Two-thirds of the respondents $(n=$ 570) reported they only walk one to four times during the day for more than five minutes. Regarding whether the participant wears glasses, the answers were comparable between "yes, bifocal", "yes, non-bifocal", and "no" with $30.01 \%, 32.41 \%$, and $37.58 \%$, respectively.

\subsection{Adverse impact on workers}

Many of the responses from the home office workers raise concern for impacts on their long-term health. More than half of the survey respondents reported their stress levels and tiredness levels have increased since the transition to a home office work environment. Specifically, $54.2 \%(n=457)$ of respondents stated their stress level had either increased slightly more than usual, somewhat more than usual, or a lot more than usual. Regarding fatigue, $50.9 \%$ $(n=429)$ of the respondents stated their tiredness level had either increased slightly more than usual, somewhat more than usual, or a lot more than usual as compared to prior to working at home due to COVID19.

Discomfort was very prevalent in the faculty and staff completing the survey (see Fig. 7). More than three-fourths of the respondents $(n=652,78.5 \%)$ stated they experienced little to no discomfort while working in their normal office setting prior to COVID-19, and $21.5 \%$ of these workers had moderate to severe discomfort in at least one region of the body. As the faculty and staff were compelled to telework, discomfort seemed to increase. While teleworking, greater than $40 \%$ of survey respondents noted moderate to severe discomfort levels in the eyes/neck/head, upper back/shoulders, and lower back regions $(46.98 \%(n=396), 49.70 \% \quad(n=419)$ $42.82 \%(n=361)$, respectively). 


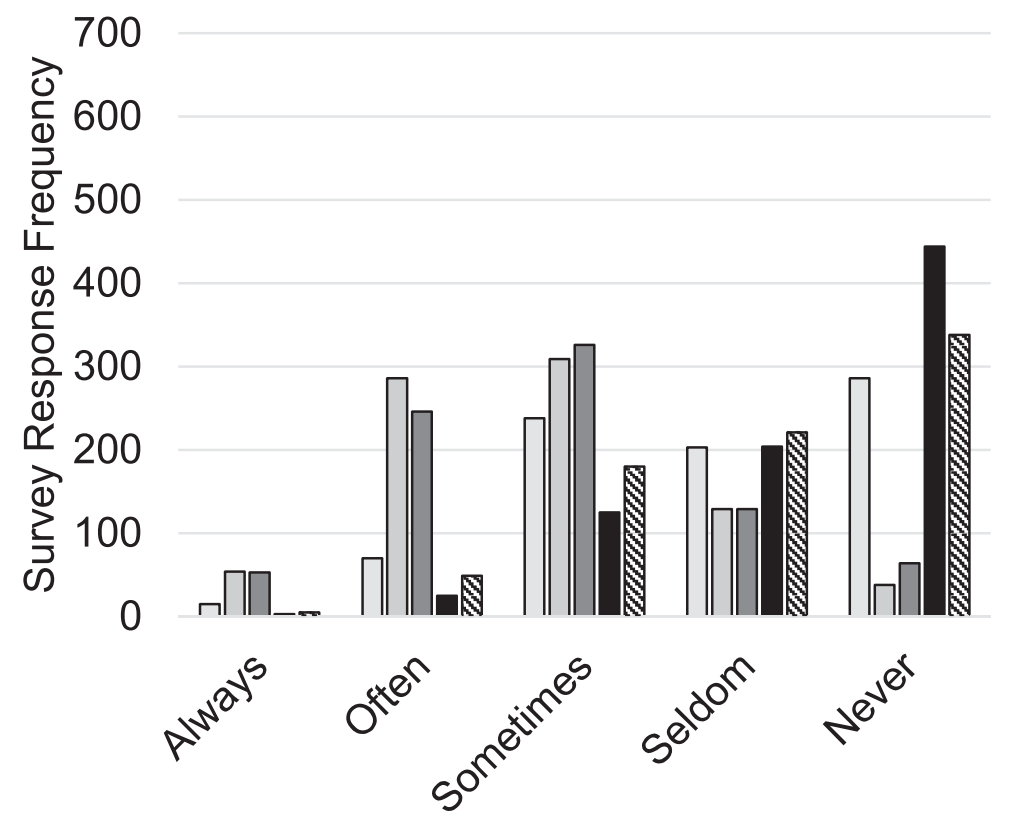

Frequency of Use

\begin{tabular}{|cc}
$\square$ Back Bent & $\square$ Head/Neck Tilted Forward \\
$\begin{array}{cc}\square \text { Head/Neck Neutral } & \text { Head/Neck Tilted } \\
\text { Position } & \text { Backward }\end{array}$ \\
$\begin{array}{c}\text { \& Head/Neck Tilted } \\
\text { Sideways }\end{array}$
\end{tabular}

Fig. 6. Frequency of time spent in a poor body posture for back and head/neck.

\subsection{Correlations}

\subsubsection{Computer devices, workstations, and input devices}

As would be expected, laptop use was inversely related to desktop computer usage $(r=-65, p<$ $0.0001)$ and tablet usage $(r=-0.11, p<0.05)$. Tablet usage was correlated with alternative device usage $(r=0.22, p<0.001)$. Use of an office chair with armrests was negatively correlated with laptop usage $(r=-0.20, p<0.0001)$ and positively related to desktop computer usage $(r=0.38, p<0.0001)$. The opposite was the case for dining room chair (laptop: $r=0.25, p<0.0001$ and desktop computer: $r=-0.25$, $p<0.0001$ ), couch (laptop: $r=0.12, p<0.001$ and desktop computer: $r=-0.15, p<0.0001)$, and bed (laptop: $r=0.08, p<0.04$ and desktop computer: $r=$ $-0.10, p<0.01)$. Usage of a couch was found to be correlated to bed usage $(r=0.34, p<0.0001)$. Significant correlations in the positive direction was found for laptop and laptop monitor usage $(r=0.44$, $p<0.0001)$, laptop and laptop keyboard $(r=0.46, p<$ $0.0001)$, laptop and laptop mouse $(r=0.39, p<$ $0.0001)$, desktop computer and external monitor $(r=$ $0.62, p<0.0001)$, desktop computer and two external monitors $(r=0.36, p<0.0001)$, desktop computer and external keyboard $(r=0.63, p<0.0001)$, desktop computer and traditional mouse $(r=0.42, p<$ $0.0001)$, office chair with armrests and external monitor $(r=0.37, p<0.0001)$, desktop computer and traditional office desk $(r=0.34, p<0.0001)$, dining chair and makeshift desk $(r=0.58, p<0.0001)$, laptop and makeshift desk $(r=0.23, p<0.0001)$, couch and no workstation $(r=0.59, p<0.0001)$, bed and no workstation $(r=0.34, p<0.0001)$, laptop monitor and no workstation $(r=0.25, p<0.0001)$, laptop 


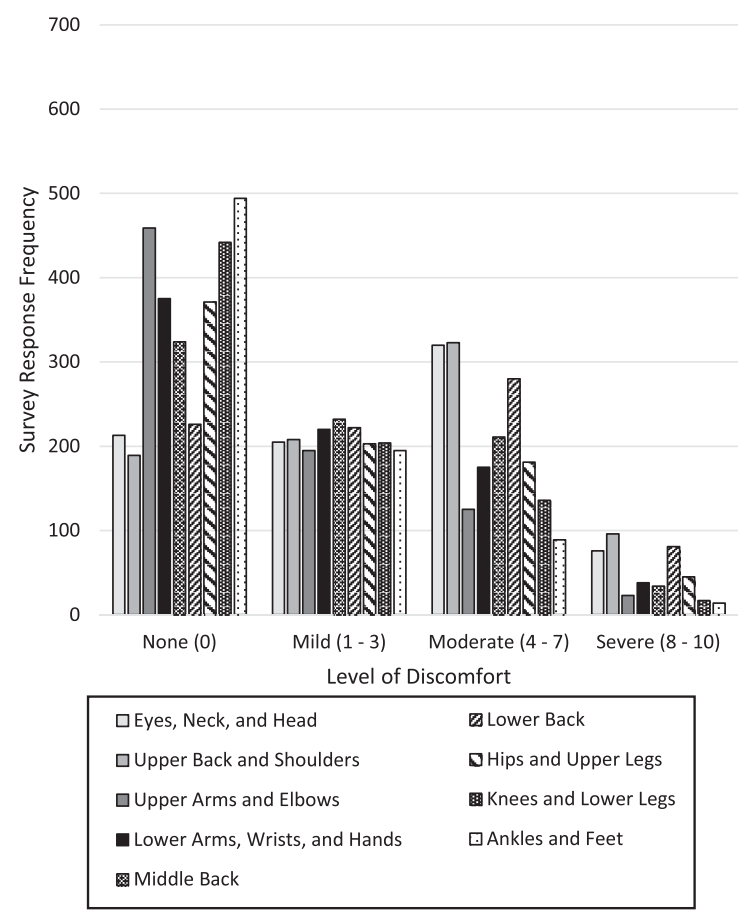

Fig. 7. Discomfort in the home office by body area.

monitor and makeshift desk $(r=0.29, p<0.0001)$, laptop keyboard and makeshift desk $(r=0.27, p<$ $0.0001)$, laptop mouse and makeshift desk $(r=0.22$, $p<0.0001)$, and traditional mouse and traditional office desk $(r=0.32, p<0.0001)$.

\subsubsection{Other factors}

Several factors were positively associated with back support including: desktop computer $(r=0.09$, $p<0.01)$, office chair with arm rests $(r=0.24, p<$ $0.0001)$, external monitor $(r=0.10, p<0.01)$, external keyboard $(r=0.14, p<0.0001)$, traditional mouse $(r=0.12, p<0.001)$, and traditional desktop $(r=0.22$, $p<0.0001)$. One key correlation was found for exposure to sharp front edge of the desk which was office chair without armrests $(r=0.10, p<0.01)$. There was a positive correlation between glare and laptop usage $(r=0.10, p<0.004)$, couch $(r=0.19$, $p<0.0001)$, bed $(r=0.12, p<0.0001)$, and makeshift desk $(r=0.20, p<0.0001)$. Adjustable armrests and lumbar support were positively correlated with desktop $(r=0.15, p<0.03)$ and office chair with arm rests $(r=0.15, p<0.002$ and $(r=0.36, p<0.0001$, respectively). There were no significant correlations with time without a break and number of times walking more than 5 min.
Table 2

Regression models for stress and tiredness variables

\begin{tabular}{lccc}
\hline \multicolumn{3}{c}{ Stress } & \\
\hline & Beta & $P$-value & $\begin{array}{c}\text { Partial } \\
\text { R-squared }\end{array}$ \\
\hline Intercept & 1.96 & & \\
Time without break & -0.12 & 0.002 & 0.01 \\
Glare & 0.25 & $<0.0001$ & 0.05 \\
Age & 0.11 & 0.001 & 0.01 \\
Laptop keyboard & 0.08 & 0.01 & 0.01 \\
\hline \multicolumn{3}{l}{ Tiredness } \\
Intercept & 1.68 & \\
Glare & 0.27 & $<0.0001$ & 0.08 \\
Bed workstation & 0.12 & 0.002 & 0.01 \\
\hline
\end{tabular}

\subsection{Regression}

\subsubsection{Stress and tiredness}

Increased age, glare, and laptop keyboard usage increase stress (Table 2). Increased time between breaks was found to actually decreases stress ( $r=$ -0.12 ). Two factors influenced the tiredness workers felt with increased glare and time working on the bed increasing the tiredness.

\subsubsection{Workplace factors impacting body discomfort}

Table 3 provides a summary of the regression models for the discomfort for the 9 body regions utilizing the office workstation factors. In all one body region (exception hips and legs), increased glare increased discomfort. Another factor that appeared to contribute to discomfort (6 out of 9 regions) was use of back support of chair where less time spent in contact increased discomfort ( $\mathrm{r}$ ranged between -0.24 to -0.47 ). Additional contributing factors of note are: 1) females had less discomfort for eye, neck, and head; hips and upper legs; and upper back and shoulders regions, 2) working in non-traditional workstations increased discomfort such as couch for eyes, neck, and head and dining chair for middle back, and 3) sit-stand workstation for lower arms, wrists, and hands. Use of adjustable armrests was protective with respect to discomfort for lower arms, wrists, and hands.

\section{Discussion}

Of the population employed by the University of Cincinnati, 843 individuals returned the surveys. From this data, an alarming proportion of employees 
Table 3

Regression models for body discomfort utilizing workplace factors

\begin{tabular}{|c|c|c|c|c|c|c|c|}
\hline \multicolumn{4}{|c|}{ Eyes, neck, and head } & \multicolumn{4}{|c|}{ Upper back and shoulders } \\
\hline & Beta & $P$-Value & $\begin{array}{c}\text { Partial } \\
\text { R-squared }\end{array}$ & & Beta & $P$-Value & $\begin{array}{c}\text { Partial } \\
\text { R-squared }\end{array}$ \\
\hline Intercept & 5.20 & & & Intercept & 4.20 & & \\
\hline Glare & 0.81 & $<0.0001$ & 0.12 & Glare & 0.69 & $<0.0001$ & 0.10 \\
\hline Back in contact with chair & -0.26 & 0.008 & 0.02 & Gender & -0.93 & $<0.0001$ & 0.04 \\
\hline Couch workstation & 0.19 & 0.05 & 0.01 & Sharp edge on desk & 0.25 & 0.04 & 0.01 \\
\hline Gender & -0.59 & 0.01 & 0.01 & Back in contact with chair & -0.31 & 0.001 & 0.02 \\
\hline \multicolumn{4}{|c|}{ Upper arms and elbows } & \multicolumn{4}{|c|}{ Lower arms, wrists, and hands } \\
\hline Intercept & 2.59 & & & Intercept & 5.06 & & \\
\hline Glare & 0.45 & $<0.0001$ & 0.05 & Glare & 0.66 & $<0.0001$ & 0.08 \\
\hline \multirow[t]{3}{*}{$\begin{array}{l}\text { Laptop with } \\
\text { external monitor }\end{array}$} & -0.13 & 0.02 & 0.01 & $\begin{array}{l}\text { Sit-Stand workstation } \\
\text { (bought) }\end{array}$ & 0.25 & 0.05 & 0.01 \\
\hline & & & & External keyboard & 0.15 & 0.05 & 0.01 \\
\hline & & & & Adjustable armrests & -0.51 & 0.05 & 0.01 \\
\hline \multicolumn{4}{|c|}{ Middle back } & \multicolumn{4}{|c|}{ Lower back } \\
\hline Intercept & 4.55 & & & Intercept & 4.51 & & \\
\hline Back in contact with chair & -0.47 & $<0.0001$ & 0.05 & Back in contact with chair & -0.46 & $<0.0001$ & 0.04 \\
\hline Glare & 0.72 & $<0.0001$ & 0.07 & Glare & 0.72 & $<0.0001$ & 0.07 \\
\hline Laptop keyboard & -0.21 & 0.01 & 0.01 & & & & \\
\hline Dining chair & 0.17 & 0.03 & 0.01 & & & & \\
\hline \multicolumn{4}{|c|}{ Hips and upper legs } & \multicolumn{4}{|c|}{ Knees and lower legs } \\
\hline Intercept & 0.17 & & & Intercept & 0.88 & & \\
\hline $\begin{array}{l}\text { Back in contact } \\
\text { with chair }\end{array}$ & -0.38 & $<0.0001$ & 0.03 & Back in contact with chair & -0.24 & 0.001 & 0.02 \\
\hline \multirow[t]{2}{*}{ Gender } & -0.58 & 0.006 & 0.01 & Glare & 0.29 & 0.0001 & 0.02 \\
\hline & & & & Time without break & -0.30 & $<0.0001$ & 0.02 \\
\hline \multicolumn{8}{|c|}{ Ankles and feet } \\
\hline Intercept & 2.16 & & & & & & \\
\hline Glare & 0.30 & $<0.0001$ & 0.03 & & & & \\
\hline
\end{tabular}

(more than 40\%) noted discomfort in various body areas, such as the: eyes/neck/head, upper back/ shoulders, and lower back while teleworking. Comparing this percentage to the fact more than $75 \%$ of respondents stated they experienced little to no discomfort in their typical office setting prior to COVID19 , it is clear there has been a dramatic increase in discomfort symptoms following the transition to telework. This increase in symptoms could certainly be explained by the transition of on-site office work to remote telework. One of the most prominent office concerns would be the extensive use of laptops ( $\sim 70 \%$ reported "always" using a laptop). Previous studies have shown usage of laptop computers, oftentimes in sub-optimal workstations caused awkward wrist postures during typing on keyboard or activation of touchpad, arms not supported placing stress on the upper back, and neck flexed to look down at the screen [11]. However, it is important to note due to the nature of the pandemic recall bias could impact the results of discomfort within the participants' responses. In a sub-set of the survey participants, pictures of the workstations for 41 faculty/staff (self-selected) were analyzed to identify actual ergonomic concerns [10]. These pictures revealed laptops were often used, resulting in poor postures due to too low of a monitor, no external keyboards, and makeshift workstations.

Correlation analysis showed strong relationships between laptop usage and suboptimal workstation conditions, namely lack of a good chair with adjustable armrests and lumbar support and reduced use of a desk or other furniture that allowed the monitor to be correctly positioned while working. Prior research has shown laptop computer usage, which is typically coupled with suboptimal workstation setups, results in awkward wrist placements while typing on a keyboard or using the touchpad, a lack of support for the arms, which in turn places stress on the upper back, and increased strain on the neck which is flexed to look down at the screen [11]. An external monitor properly positioned with top of screen at eye height and directly in front of the worker would reduce the awkward postures of arms, neck, and back likely contributing to the high levels of discomfort. Further, the 
benefits of an external mouse and keyboard would enable an individual to maintain proper more neutral hand postures as well as when an external monitor is not available would allow laptop monitor to be elevated to an appropriate height. The impact of a poor monitor height maybe further exacerbated by high number of people with bifocals (30\%) which was significantly higher than previous studies $(10 \%)$ [19].

A proper workstation should consist of an external monitor positioned with top of screen directly in front of the worker at eye level and would correct the awkward postures of the arms, neck, and back likely contributed to the high levels of discomfort [10]. Additionally, the use of an external mouse and keyboard would enable an individual to maintain more neutral hand postures, and (in the absence of an external monitor) would allow a laptop monitor to be elevated to the appropriate height [10]. Another major potential contributor to adverse health was the lack of a good ergonomic chair that includes adjustable armrest, five casters, good back with a lumber support, and adjustable seat height. Respondents using a laptop were statistically more likely to make a poor selection in seating such as a dining chair, a couch, or a bed, if they used a worksurface at all, as opposed to a traditional desk.

Laptop use was strongly correlated with nontraditional workstations such as a bed or couch which did not provide adequate lumbar support or proper elevation of the monitor. Seating positions that did not provide good back support (measured as frequent back contact with a chair back) showed a higher likelihood of discomfort in the eyes, neck, and head; upper back and shoulders, lower back; hips and upper legs; and knees and lower legs. On the other hand, laptops were inversely correlated with adequate lumbar support, glare, and chairs without armrests. This indicates not only is there a high level of use of laptops but oftentimes they are utilized in less than optimal ergonomic conditions such as the back bent forward, neck bent forward or sideways, and was also correlated with experiencing increased levels of stress and tiredness since beginning work from home.

The use of a desktop had positive associations with office chairs with armrests, a chair with armrests, and a chair with lumbar support. As a result, while traditional office workstations (e.g. desktop computer, external monitor, external keyboard and mouse, and office chair with adjustable armrests) were not widely used, they were associated with less poor ergonomic concerns (e.g. glare, no lumbar support). Desktop use also showed a higher likelihood of using one or more external monitors, an external keyboard, and traditional mouse, as well as a traditional or sit/stand desk-all of which contributed to a decrease in physical discomfort particularly in the lower arms, wrists, and hands, as well as areas affected by the head and neck being bent forward. In a time of expedited shift to the home and limited resources due to the down turn in the economy, many individuals have shifted to makeshift workstations which many not adequately protect workers [20].

Several key results were found from the regression analyses, many of which centered around the idea the principles of good workstation seem to disappear as more elements not designed for the specific task are introduced. First, glare was a dominant stressor for having body discomfort in most of the body regions (exception upper leg and hips). Glare appeared to impact several body postures which produced more flexion in the neck and back as well as neck bent sideways. These postural responses were also found to be related to the discomfort, thus, glare seems to perpetuate through body adjustments that lead to the increased discomfort. Second, lack of having contact with the back of the chair was found to impact the discomfort in most body regions (all but upper arms and elbow; lower arms, wrist, and hands; ankles and feet). Less than half of respondents always or often used an office chair with armrests and less than a quarter of respondents used an office chair with adjustable armrests. The relationship between lack of back support and discomfort would likely be driven by the increased muscle stress required to support the different body regions. Moreover, while a slight majority of respondents reported typically using a traditional desk to complete work, many utilized makeshift or improvised work surfaces, such as a kitchen table or counter, card tables, or from living room furniture or bed. When a workstation becomes more and more makeshift, the principles of good office ergonomics appear to dissipate, resulting in poor postures and increased discomfort. Makeshift workstations may have led to uses of components in manners for which they were not originally designed or not fully adjusted to the worker appropriately [20].

Third, the significant effect of sharp edge for upper back and shoulder would likely be due to changes in arm posture in response to contact stress on the forearms. Fourth, distal upper extremity discomfort was reduced by adjustable armrests and use of external keyboard. Finally, dining room chair was significantly related to middle back discomfort where more 
time in the chair increased pain, likely due to the lack of back support. In all, many of the poor ergonomic conditions were related to increased discomfort.

A couple of other negative outcomes for home office work is the increase in stress and tiredness. This increase in adverse responses may reflect additional complexities workers face in a work-home environment, such as less work/life balance and reduced personal/family success compared to individuals in a typical office setting [6]. The slight majority of respondents stating their tiredness levels have increased since the transition to telework began and the slight majority who reported increased stress levels may reflect the complexities workers face in a work-home environment. Prior research showed working at home caused less work/life balance and reduced personal/family success compared to individuals in a typical office setting [6]. This could be caused from employees lacking satisfactory physical boundaries at their residence. Possibilities of working towards stress minimization could come in the form of discussing with one's supervisor the opportunity to modify one's own daily schedule, creating a more "results-oriented" mindset [7]. Again, glare appears to be a contributor to both stress and tiredness. Lack of breaks was also found to significantly increase stress. Individuals could also find ways to integrate more physical activity into the day as roughly two-thirds of respondents reported they only walk for more than a five-minute interval up to four times a day [7]. It is important to move every 30 minutes to increase large muscle activation and reduce static postures, and most likely reduce stress [21]. Increase time working on the bed also increases the tiredness, likely due to poor static postures that need to be held.

The results of this study demonstrate there are opportunities for improvement in ergonomics within the home office. Proper training in ergonomics has been found to be effective in reducing discomfort in teleworkers and in-person office workers alike [22, 23]. With $25-40 \%$ of respondents noting they typically use dining chairs, recliners, a laptop keyboard, or poor worksurfaces, the importance of increasing office ergonomic awareness, as well empowering home office workers to make positive changes is certain [24]. As the effects of the pandemic on workforces continue to evolve with little certainty, there is a strong case that improved workspaces will not only be beneficial for the workers but may also be financially advantageous for employers. Providing better support for the physical and mental health of their employees could reduce potential downtime and compensation claims attributed to injuries from sustained strain in non-ergonomic conditions.

\subsection{Limitations}

The survey used for this analysis was provided to only the faculty, staff, and administration of a single, public, urban university within the U.S. For this reason, the findings of this study may not completely reflect workers in general but do provide insight into common concerns of home offices. For example, individuals employed in more rural settings may have poor home internet reliability and could have fewer options within the household with which to create a makeshift home office.

Second, the survey was based on the perceptions of the individuals, especially with respect to the postures and discomfort. Subjective perceptions regarding the organization of the home office have the potential for bias as they relate to the adverse impact of being home and COVID-19. Perceptions of using various devices were likely more accurate but biased as it can be difficult to estimate "how much" they were used, except in the case when they only used a set-up with one device (e.g. laptop only at a desk). Future work should investigate how employees are working in offices at home as the pandemic continues beyond the initial stay-at-home phase. The increases in stress and fatigue reported could be explained by COVIDrelated (fear of infection, fear of job loss) stressors rather than due only to the stress of moving to a home office.

Third, since the pandemic situation created a mass need for telework among the "non-essential" industries all data collected was retrospective. Since pre-COVID-19 telework data evaluating similar ergonomic issues at the University of Cincinnati was not available, a control group for the study could not be assigned. It is likely that planned telework pre-COVID-19 would include a better set up for a home office compared to make shift telework initiated by the pandemic. Employers and employees would likely be more aware of items needed for a successful home office for a job designed for telework compared to an in-office work environment.

Finally, while 843 is a large number of responses, it represented a less than $10 \%$ response rate. The relatively low percentage could mean the results were subjected to selection bias. If a bias exists, the percentage of discomfort and poor postures maybe over estimated due to negative effect. 


\section{Conclusion}

The results from this study illustrate the apparent level in discomfort experienced by university faculty, staff, and administration brought about by the ongoing COVID-19 pandemic. Large increases in discomfort levels following the stay-at-home orders were observed. Many potential sources of this increase in discomfort were reported such as wide use of laptops, working at sub-optimal workstations such as couches, beds, and kitchen countertops. Telework has led to many adverse working conditions such as laptops with monitors too low, chairs without armrests, hard edge on desktops surfaces, and long static postures due to lack of routine breaks. As we have converted to home offices, employees don't have the resources to adequately set up workstations at home. Companies and institutions need to ensure workers have proper equipment including an adjustable office chair with armrests, a monitor that can be set to eye height, and an external keyboards and mouse. Additionally, it is recommended companies and institutions provide proper ergonomic training to their employees to prevent potential musculoskeletal disorders from developing.

\section{Recommendations}

A few recommendations that could be helpful for the home-office worker:

- Placing a pillow on the seat can elevate the seat height to an appropriate height.

- Placing a pillow or rolled up towel behind your back may provide lumbar and back support with a chair that does not have lumbar support built into the chair back.

- Wrapping armrests when they are low and not adjustable may help for better arm positioning.

- Moving your chair closer to the desk or table can encourage maintaining the back against the back of the seat.

- If a laptop is too low in relation to head height, placing a lap desk or large pillow under the laptop to raise the monitor when using it on the lap should help.

- Using an external keyboard and mouse will help with reducing awkward wrist postures.

- An appropriate standing workstation should have the top of the monitor at eye height and directly in front, keyboard at a height so that forearms are parallel to the ground (approximately $90^{\circ}$ elbow angle), and a soft or rounded front edge to the working surface.

- If obtaining a new chair or identifying an appropriate sitting workstation at home is not possible, rotating between a poor sitting workstation and a standing workstation would be the next best practice. There are many simple, makeshift standing workstations available in the home, including implementing the use of an ironing board, a kitchen counter, the top of a piano, a clothes basket placed upside down on a table or desk or a large box under the laptop.

\section{Conflict of interest}

The authors have indicated they have no potential conflicts of interest to disclose.

\section{Funding}

This work was supported by the National Institute for Occupational Safety and Health through the University of Cincinnati Education and Research Center (\#T42OH008432).

\section{References}

[1] Population estimates. United States Census Bureau Quick Facts. D.C.: 2019. [cited 2020 May 18]. Available from https://www.census.gov/quickfacts/fact/table/US\#

[2] The Economics Daily, 24 percent of employed people did some or all of their work at home in 2015. Bureau of Labor Statistics, U.S. Department of Labor: 2016 [cited 2020 May 18]. Available from: https://www.bls.gov/opub/ted/2016/24-percent-ofemployed-people-did-some-or-all-of-their-work-at-homein-2015.htm.

[3] Belzunegui-Eraso A, Erro-Garces A. Teleworking in the context of the Covid-19 crisis. SUSTDE. 2020;12(3662). Available from: https://doi.org/10.3390/su12093662.

[4] WHO Timeline - COVID-19. WHO (World Health Organization); 2020 [cited 2020 May 13]. Available from https://www.who.int/news-room/detail/27-04-2020who-timeline-covid-19.

[5] Global Work-from-Home Experience Survey. Global Workplace Analytics; 2020 [cited 2020 May 18]. Available from https://globalworkplaceanalytics.com/work-at-homeafter-covid-19-our-forecas.

[6] Hill EJ, Ferris M, Martinson V. Does it Matter Where you Work? A Comparison of How Three Work Venues (Traditional Office, Virtual Office, and Home Office) Influence Aspects of Work and Personal/Family Life. J Vocat Behav. 2003;63(2003):220-241. Available from: https://doi.org/10.1016/S0001-8791(03)00042-3. 
[7] Friedman SD, Christensen P, DeGroot J. Work and Life: The End of the Zero-Sum Game. Harv Bus. 1998;76(6):119-29. Available from: http://worklife.wharton.upenn.edu/wpcontent/uploads/2012/11/Friedman-et-al-The-End-of-theZero-Sum-Game-HBR-1998.pdf.

[8] Asundi K, Odell D, Luce A, Dennerlein JT. Notebook computer use on a desk, lap and lap support: Effects on posture and comfort. Ergonomics. 2010;53:74-82. Available from: https://doi.org/10.1080/00140130903389043.

[9] Rodrigues MS, Leite RD, Lelis CM, et al. Differences in Ergonomic and Workstation Factors Between Computer Office Workers With and Without Reported Musculoskeletal Pain. Work. 2017;57(4):563-72. Available from: https://content.iospress.com/articles/work/wor2582.

[10] Davis KG, Kotowski SE, Daniel D, Gerding T, Naylor $\mathrm{J}$, et al. The Home Office: Ergonomic Lessons From the "New Normal". Ergon. Des. 2020 Jul. 3; https://doi.org/ 10.1177/1064804620937907

[11] Werth AJ, Babski-Reeves K. Assessing Posture While Typing on Portable Computing Devices in Traditional Work Environments and at Home. Proceedings of the Human Factors and Ergonomics Society 56th Annual Meeting. 2012. Available from: https://doi.org/10.1177/ 1071181312561223.

[12] Jacobs K, Johnson P, Dennerlein J, Peterson D, Kaufman J, et al. University Students' Notebook Computer Use. Appl Ergon. 2009;40:404-9. Available from: https://doi.org/10.1016/j.apergo.2008.11.009.

[13] Lewis RJ, Fogleman M, Deeb JM, Crandall E, Agopsowicz D. Effectiveness of a VDT Ergonomics Training Program. Int J Ind Ergon. 2001;27(2):119-31. Available from: https://doi.org/10.1016/S0169-8141(00)00043-3.

[14] Norman K, Nilsson T, Hagberg M, Tornqvist EW, Toomingas A. Working Conditions and Health Among Female and Male Employees at a Call Center in Sweden. Am J Ind. 2004;46(1):55-62. Available from: https://doi.org/10. 1002/ajim.20039

[15] Rempel DM, Krause N, Goldberg R, et al. A Randomized Controlled Trial Evaluating the Effects of Two Workstation Interventions on Upper Body Pain and Incident Musculoskeletal Disorders Among Computer Operators. J Occup Med. 2006;63(5):300-6. Available from: http://dx.doi.org/10.1136/oem.2005.022285.
[16] Gerr F, Monteilh CP, Marcus M. Keyboard Use and Musculoskeletal Outcomes Among Computer Users. J Occup Rehabil. 2006;16(3):265-77. Available from: https://doi.org/10.1007/s10926-006-9037-0.

[17] Ijmker S, Huysmans MA, Blatter BM, et al. Should Office Workers Spend Fewer Hours at their Computer? A Systematic Review of the Literature. J Occup Med. 2007;64(4):211-22. Available from: http://dx.doi.org/ 10.1136/oem.2006.026468.

[18] UC Facts. University of Cincinnati; 2019 [cited 2020 May 18]. Available from https://www.uc.edu/about/ factsheet.html.

[19] Hales TR, Sauter SL, Peterson MR, Fine LJ, Putz-Anderson $\mathrm{V}$, et al. Musculoskeletal disorders among visual display terminal users in a telecommunications company. Ergonomics. 1994;37(10):1603-21. Available from: https://doi.org/ 10.1080/00140139408964940.

[20] Ye L, Petrovic M, Dainoff MJ, Mark LS. Guerilla Ergonomics: Perceiving the Affordances for Workplace Design. In: Dainoff M.J. (eds) Ergonomics and Health Aspects of Work with Computers. EHAWC 2007. Lecture Notes in Computer Science, vol. 4566. Springer, Berlin, Heidelberg; 2002. Available from: https://doi.org/10. 1007/978-3-540-73333-1_21.

[21] Davis KG, Kotowski SE. Postural Variability: An Effective Way to Reduce Musculoskeletal Discomfort in Office Work. Hum Factors. 2014;56(7):1249-61. Available from https://doi.org/10.1177/0018720814528003.

[22] Harrington S, Walker B. The Effects of Ergonomics Training on the Knowledge, Attitude, and Practices of Teleworkers. J Saf Res. 2004;35(1):13-22. Available from: https://doi.org/10.1016/j.jsr.2003.07.002

[23] Greene BL, DeJoy DM, Olejnik S. Effects of an Active Ergonomics Training Program on Risk Exposure, Worker Beliefs, and Symptoms in Computer Users. Work. 2005;24(1):41-52. Available from: https://content. iospress.com/articles/work/wor00386.

[24] Snodgrass J. Office Ergonomics: The Influence of Assessment and Education on Musculoskeletal Discomfort and Workstation Configuration. Am J Occup Ther. 2019; 73(4):7311515356p1-7311515356p1. Available from: https://doi.org/10.5014/ajot.2019.73S1-PO5024 